RESEARCH ETHICS

\title{
Laboratory animals and the art of empathy
}

D Thomas

J Med Ethics 2005;31:197-204. doi: 10.1136/jme.2003.006387

Consistency is the hallmark of a coherent ethical philosophy. When considering the morality of particular behaviour, one should look to identify comparable situations and test one's approach to the former against one's approach to the latter. The obvious comparator for animal experiments is non-consensual experiments on people. In both cases, suffering and perhaps death is knowingly caused to the victim, the intended beneficiary is someone else, and the victim does not consent. Animals suffer just as people do. As we condemn non-consensual experiments on people, we should, if we are to be consistent, condemn non-consensual experiments on animals. The alleged differences between the two practices often put forward do not stand up to scrutiny. The best guide to ethical behaviour is empathy-putting oneself in the potential victim's shoes. Again to be consistent, we should empathise with all who may be adversely affected by our behaviour. By this yardstick, too, animal experiments fail the ethical test.

\footnotetext{
Correspondence to: Mr D Thomas; wdcthomas@onetel.com

Received

3 September 2003

In revised form

1 November 2003

Accepted for publication

27 November 2003
}

11 ath not a Jew eyes? hath not a Jew hands, organs, dimensions, senses, affections, passions? fed with the same food, hurt with the same weapons, subject to the same diseases, healed by the same means, warmed and cooled by the same winter and summer, as a Christian is? If you prick us, do we not bleed? ... if you poison us, do we not die?" Shylock, The Merchant of Venice

\section{INTRODUCTION}

It is not clear whether Shylock would have been opposed to animal experiments. But he should have been, if he was being consistent in his ethics. He understood that, when determining how we should treat others, we should put ourselves in their shoes and ask how we would feel in the same circumstances. In other words, we should empathise. Just as Jews suffer in the same way as Christians if they are poisoned, so do animals. Like Christians and Jews, animals bleed if pricked.

In this article I will argue that consistency is the hallmark of a coherent ethical philosophy experiments is non-consensual experiments on people. We regard the latter as unethical, so we should the former. As a society we have no difficulty in empathising with the victims of human experiments. Horror at the thought of being experimented upon is no doubt why we regard the practice as abhorrent. It should not and that the obvious comparator with animal take a big leap of imagination to empathise with the victims of animal experiments as well. In short: if we would not want done to ourselves what we do to laboratory animals, we should not do it to them.

\section{Animals suffer}

Crucially for the debate about the morality of animal experiments, non-human animals suffer just as human ones do. Descartes may have described animals as "these mechanical robots [who] could give such a realistic illusion of agony" (my emphasis) but no serious scientist today doubts that the manifestation of agony is real, not illusory. Indeed, the whole pro-vivisection case is based on the premise that animals are sufficiently similar to us physiologically, and for some experiments behaviourally too, for valid conclusions to be extrapolated from experimenting on them.

Of course, the nature and degree of suffering will not always be identical. Some species of animal will suffer less than people in equivalent situations, and people probably experience greater distress at witnessing someone close to them suffer than many animals would, adding to the totality of suffering in the human context.

Equally, however, lab animals will sometimes suffer more than people would, sometimes physically, sometimes psychologically. Unlike Terry Waite, who composed novels in his head as a coping mechanism during his five years of captivity, ${ }^{1}$ animals are (as far as we know) not fortified by a sense of mission or injustice and do not know that their suffering will eventually come to an end.

The law has sometimes been slow to recognise that animals suffer. However, the European Union now accepts that animals are sentient beings and therefore qualitatively different from other traded "products". ${ }^{2}$ The European Patent Convention and the European Patent Directive ${ }^{3}$ each acknowledge that the genetic engineering of animals raises moral issues precisely because the engineered animals are liable to suffer; in principle, a patent could be refused on these grounds. ${ }^{4}$ And, in the UK, a licence to conduct an experiment on animals is only required if it is liable to cause "pain, suffering, distress or lasting harm" ${ }^{5}$ Nearly three million laboratory animals fell within this definition in 2003.

Suffering, indeed, lies at the heart of all morality. We have moral codes precisely because our behaviour may adversely affect others. It is not surprising, therefore, that animal

Abbreviations: APC, Animal Procedures Committee; CMP, Coalition for Medical Progress; HLS, Huntingdon Life Sciences; RDS, Research Defence Society. 
experimentation has become one of the ethical issues of our time. In a recent survey carried out by MORI for the Coalition for Medical Progress (CMP), over two thirds of respondents said they were either very or fairly concerned about the issue. The Animal Procedures Committee (APC), the government's advisory body, has recently entered the ethical debate in its report on the cost:benefit test which lies at the heart of the Animals (Scientific Procedures) Act 1986. " ${ }^{6}$ "ost", of course, refers principally to animal suffering. The APC's contribution is intelligent but flawed in one crucial respect, as I will explain.

\section{The battle for hearts and minds}

The CMP is a newly formed coalition of multinational pharmaceutical and contract testing companies (such as GlaxoSmithKline (GSK) and Huntingdon Life Sciences (HLS)), pro-vivisection pressure groups such as the Research Defence Society (RDS), bodies funding animal research like the Medical Research Council, and a trade union, Amicus (which has members at HLS). The fact that yet another lobby group has been set up shows how crucial the battle for hearts and minds on this issue has become. It is fair to point out that many CMP members have a large financial interest in animal experiments.

It is beyond dispute that the present government, ever ready to promote British business, has recently entered the propaganda fray firmly on the side of animal researchers. It contributed an astonishing $£ 85000$ towards the cost of the MORI survey. ${ }^{7}$ In 2002 the Prime Minister publicly supported Cambridge University's controversial planning application to extend its primate facility. Rather embarrassingly for him, his intervention came on the very day that BBC's Newsnight carried the British Union for Abolition of Vivisection's exposé of the suffering endured by primates at the university's existing facility.

\section{The ethical issue in a nutshell}

So the battle lines are drawn, sometimes literally. Although there are, increasingly, arguments around the scientific efficacy of vivisection, at root it is an ethical issue: is it justifiable to inflict suffering on animals when it is not for their benefit but rather for the benefit of those doing the inflicting (or those they purport to represent)? As with all ethical dilemmas, the proposition is capable of neither proof nor disproof. If a person's political opinions are merely the rationalisation of his or her instinctive response, so it is with matters of ethics. We react to a given situation at an emotional level and then find the reasons to justify our position. The assumptions we make in addressing an issue will often determine the outcome, and those assumptions will often be the product of our cultural conditioning. Vivisection is no different from other issues in this respect.

The 18th century Scottish philosopher David Hume put it like this:

\section{"The approbation of moral qualities most certainly is not deriv'd from reason, or any comparison of ideas; but proceeds entirely from a moral taste, and from certain sentiments of pleasure or disgust, which arise upon contemplation and view of particular qualities or char- acters. ${ }^{\prime \prime}$}

Adam Smith's view was that the general rules of morality are founded upon experience of what, in particular instances, our moral faculties and sense of propriety approve or disapprove. ${ }^{9}$ None of this means, of course, that rational thought has no place when considering ethical issues. As a minimum, we should, firstly, ensure that we have sufficient facts to make a reasonable judgement; and, secondly, strive for consistency across ethically comparable issues. The debate about animal experiments suffers from a deficiency in both these prerequisites, as I will try to explain.

I will focus on those animal experiments which can truly be said to be designed to address particular human diseases. They are, in fact, a minority of those carried out but it is here that the rival ethical positions are most sharply engaged.

\section{INFORMATION}

\section{A secret system}

Animal experiments in this country are shrouded in secrecy. Under section 24 of the Animals (Scientific Procedures) Act 1986, the Home Secretary could be sent to prison for up to two years were he to disclose information given to him in confidence by a researcher. The RDS advises researchers to mark everything they send the Home Office "in confidence" to try to prevent disclosure. A few years ago, Smith Kline French (as it then was) took a judicial review all the way to the House of Lords in an attempt to stop the medicines regulator even referring to test data (which SKF had supplied) when considering applications from other companies. ${ }^{10}$ Fortunately the attempt failed, but this is the secrecy mentality. Occasionally companies openly admit that they prefer their rivals to conduct "blind alley" research, irrespective of the cost to lab animals. ${ }^{11}$

The Home Office claims that it makes its own judgement about what is confidential, but usually seems to find a reason to join in the conspiracy of silence.

The outcome of some research is published, of course, but only if the researcher finds it advantageous to do so. He or she is unlikely to highlight the animal suffering involved. Negative results are rarely published. As result, duplication is rife, as international institutions and the industry itself now acknowledge. Where results are published, an article in the $B M J$ has recently highlighted the flaws in the system. ${ }^{12}$ The authors concluded: "Systematic bias favours products which are made by the company funding the research. Explanations include the selection of an inappropriate comparator to the product being investigated and publication bias."

The public is therefore denied the information on which to make sound ethical judgements about animal experiments. It has to rely on the media, which traditionally prefers easy sensationalism to painstaking investigation and stories about animal rights militancy to serious argument. Animal protection groups feel they have to conduct undercover investigations to educate the public.

\section{The ethical judgement at the heart of the legislation} Crucially, the culture of secrecy means that the legislation cannot work properly. The cost:benefit test is a moral judgement. Before he grants a licence for animal experiments, the Home Secretary is enjoined to weigh the likely "adverse effects" on an animal against the likely benefits of an experiment. ${ }^{13}$ That is, of course, a value laden judgement. How much suffering (if any) is acceptable? Does it depend on the species? What about the fact that the animal may die in the experiment, or be killed when it is no longer required? Should commercial benefit suffice? Should society just do without certain products, such that we do not need to worry about their safety? What about fundamental research, from which the benefits are by definition speculative?

There is no arithmetical formula to be applied to these ethical questions. In a mature democracy, how they are answered should reflect informed public opinion. But, this is not possible if the public does not really know what is going on and has no opportunity of influencing regulatory decisions, at however general a level. According to the Home Office, most of its inspectors-who in practice run the system-have previously held licences to experiment on 
animals, and therefore inevitably bring a pro-vivisection ethical perspective to their task.

Many believe that the government should publish detailed information about animal experiments-what they involve for the animals, their purpose, and their results-unless the researchers can, in an individual case, make out a strong objection. That would reflect the presumption of openness contained in the Freedom of Information Act 2000 (FOI Act), which has just come fully into effect. Information can be made public in anonymised form, in order to protect researchers from any risk of attack; information which is truly commercially sensitive can be omitted for as long as it retains such sensitivity.

Only in this way can there be the informed debate essential for formulation of ethical principles. It remains to be seen how much difference the FOI Act will make.

\section{THE NEED FOR CONSISTENCY}

So, the first prerequisite to a reasoned ethical judgementthe availability of sufficient information-is missing with animal experiments. What about consistency across comparable issues?

Most people would accept that an ethical philosophy should be internally consistent, insofar as possible, and that similar cases should be treated alike. Otherwise, the philosophy is likely to be opportunistic and self serving. To paraphrase John Donne: no ethical issue is an island.

In reaching our view about animal experiments, we should therefore search for a valid comparator and test our view about the former against our view of the latter. The obviousand I believe correct-comparator is non-consensual experiments on people. In both cases, suffering and perhaps death is knowingly caused to the victim, the intended beneficiary is someone else and the victim does not consent.

The APC rightly raises the question of consistency in its discourse on the ethics of vivisection. ${ }^{6}$ However, it chooses the wrong comparator. It suggests that the "appropriate point of comparison should perhaps be with an 'improved' food animal industry". Certainly, there is an ethical overlap between the way we treat food animals and the way we treat lab animals. However, the much more pertinent comparator is non-consensual experiments on people and it is surprising that the APC missed it.

\section{Recent examples of non-consensual experiments on people}

Recent history has witnessed many examples of nonconsensual experiments on people. For example:

- the barbaric experiments carried out by Nazi and Japanese scientists during the second world war;

- the long running syphilis experiments on black people in Alabama over four decades up to the 1970s;

- the radiological experiments conducted at the Burden Neurological Institute in Bristol during the 1950 and 1960s by British scientists for the US Office for Naval Research. According to The Ecologist, holes were drilled at random through the skulls and into the brains of the institute's patients. Steel electrodes, which had been coated with a radioactive chemical, were then sent deep into the brain via these holes, and electric shocks pumped through them. Some of the patients later had tumours deliberately induced in their brains. ${ }^{14}$

Sometimes, the human victim gives no consent at all; on other occasions, he or she may give consent but not on an informed basis. In November 2001, BBC Radio 4's File on Four carried a damning report on the practice of some pharmaceutical companies, particularly in Eastern Europe and
Africa, of abusing the principle of informed consent in clinical trials, including with children and mentally vulnerable people. Animals of course, cannot give any form of consent-informed or otherwise. I will return to the question of consent because it is central to the debate.

\section{Why experiments on people and on animals are comparable}

Some people will argue that, despite the superficial similarities, non-consensual experiments on people and experiments on animals are not ethically comparable. I have described these arguments below.

\section{People have greater value than animals}

It is said that, on the one hand, all people have equal intrinsic value $^{15}$ and that, on the other, all people have greater value than all (non-human) animals. So, it is concluded, experimenting on people is unethical whereas experimenting on animals is ethical. There are two points here. Firstly, judging relative value is a subjective, wholly unscientific exercise, not least because the criteria one chooses will almost inevitably determine the outcome. There is no set of obviously correct objective criteria ready to be plucked off the shelf. It rather depends who you ask. Just as for each human being our own existence is inevitably the most important, however altruistic we may try to be, to the laboratory rat its existence matters more than anyone else's.

Secondly, and more importantly, why should the fact (if this is what it is) that A has more value than B mean that A is at liberty to cause pain to B for A's benefit? This is the crucial gap in logic which pro-vivisectionists rarely address. Let us accept for the sake of argument that it was provable that the human species was more important than other specieswhether because people generally (though not always) have greater capacity for rational thought, may have greater self awareness, are better able to empathise, or have more sophisticated culture. It is not explained why those attributes mean that we can cause pain to those we relegate further down the hierarchy of value. And, if cruel exploitation of other species is justified on a relative value basis, then, logically, so must cruel exploitation within our species. Some people, indisputably, have greater capacity for rational thought, have greater self awareness, are better able to empathise, or have a deeper cultural appreciation than other people. However, most people do not conclude that the more endowed are for that reason entitled to cause pain to the less endowed for their own benefit.

The racist, the religious fundamentalist, and the misogynist do, of course, discriminate in their treatment of others according to the hierarchies of value they espouse. The majority of people may profoundly disagree with these hierarchies, but we cannot prove empirically that they are misconceived. Once one has breached the moral dam by allowing relative value to be the justification for cruel behaviour in one situation (vivisection), there is no rational basis on which one can tell someone that he does not have the right to be cruel to another person he genuinely (if misguidedly) believes to be of lesser value.

The important point is that the Nazis experimented on Jews because they regarded them as being of less value; those carrying out syphilis experiments on black men in Alabama no doubt privately justified them on the basis that they were "only" blacks. The US Bill of Rights deemed slaves to be worth only half a person, with the predictable exploitative results. In Honduras, Guatemala, and Brazil they kill street children by the thousand, because, after all, they are "only" street children, of no more value than last night's rubbish.

In truth, relative value is a very dangerous criterion for making ethical judgements. 


\section{People are more intelligent than animals}

Supporters of vivisection also point out that people are more intelligent than animals. This, it is claimed, is a morally distinguishing feature. It is, of course, true that people are generally more intelligent than animals (at least according to our own perception of intelligence). However, intelligence is a morally neutral attribute, not least because no moral choice is exercised in acquiring it. We do not give greater rights to the Nobel prize winning scientist than to the unemployed labourer. As Jeremy Bentham put it over 200 years ago in his well known epithet (his italics):

\section{"The question is not, Can [animals] reason? Nor, Can they talk?, but, Can they suffer?"16}

In any event, as Bentham noted, some animals are clearly more intelligent than some people. For example, many animals are more intelligent than people with severe learning disabilities or advanced senile dementia. If intelligence were the determining factor, it would be at least as justifiable to experiment on those people as on those animals.

\section{Only people can exercise responsibility}

A linked argument is that, in the mantra of New Labour, rights and responsibilities are the flip sides of the same coin. No one is entitled to enjoy rights unless also willing to exercise responsibility. As people can and do exercise responsibility, they should, it is argued, therefore enjoy the right of not being experimented upon; animals, on the other hand, often do not exercise responsibility (in the way we understand that concept) and are therefore entitled to no concomitant right.

In fact, there is no logical reason why one's right to protection from physical harm should be conditional on what one can give back. No sensible person would deny babies, the mentally handicapped, or the comatose protection from harm because they cannot exercise responsibility.

In truth, there is no ethically relevant criterion which differentiates experimenting non-consensually on people from experimenting on animals. Ultimately, all that the proponent of vivisection has to fall back on is the fact that humans belong to one species and other animals belong to other species: "we are human and they are only animals". This is a truism but one only has to state it to see that it has no intrinsic moral relevance. There may be a natural inclination, even a genetic disposition, to "protect one's own", but as Richard Dawkins acknowledged in The Selfish Gene, ${ }^{17}$ speciesism (the word first coined by Richard Ryder) has "no proper basis in evolutionary biology". Why, then, do we allow it to determine our ethics?

\section{INFORMED CONSENT AND BENEFIT Consent by people}

As I have indicated, the question of consent lies at the heart of the debate about experiments on people and experiments on animals. Experiments on people are sometimes permitted by law and supported by accepted norms. Indeed, the Declaration of Helsinki: Ethical principles for medical research involving human subjects (the Helsinki Declaration), as amended in October 2000, says that "[m]edical progress is based on research which ultimately must rest in part on experimentation involving human subjects". However, consent is crucial; without it, the experiment may not be carried out. There are three types of situation where consent is relevant in the case of experimental treatment on people:

- Healthy volunteers. Healthy individuals-typically students needing money-take part in trials for new drugs for which they have no therapeutic need. Companies such as GSK advertise for volunteers in publications such as the Big Issue. The Helsinki Declaration emphasises the importance of informed consent: "each potential subject must be adequately informed of the aims, methods, sources of funding, any possible conflicts of interest, institutional affiliations of the researcher, the anticipated benefits and potential risks of the study and the discomfort it may entail". Consent can be withdrawn at any time "without reprisal". Similarly, the Nuremberg Code, which arose out of the post-war Nuremberg Trials, says that "[t]he voluntary consent of the human subject is absolutely essential". Again, the basic principle is that consent can be withdrawn

- Patients who have capacity. Patients sometimes consent to treatment which, although experimental, may benefit them. People suffering from AIDS provide the obvious example. The Helsinki Declaration describes this as "medical research combined with medical care". Additional safeguards are put in place. The benefits and risks of the procedure in question must be tested against the best current prophylactic, diagnostic, and therapeutic methods and the patient must be given access to the best treatment identified by the study at its conclusion. Again, informed consent is key. The patient must be told which aspects of his care are related to the research.

- Patients who do not have capacity. The Helsinki Declaration provides that "[s]pecial attention is ... required for those who cannot give ... consent for themselves". Presumably, experimentation is only permitted where the person without capacity stands to benefit directly from the process. In the UK, the law gives a high level of protection to patients without capacity, even for non-experimental treatment. For example, under section 58 of the Mental Health Act 1983 a registered medical practitioner, before embarking on a course of psychiatric treatment for a patient who is incapable of understanding its nature, purpose, and likely effect, must consult two other people who have been professionally concerned with the patient. It must be convincingly shown that the treatment is in the patient's best interests. ${ }^{18}$ In some circumstances the consent of the High Court must be obtained before treatment is given to patients lacking capacity. What happens is that, where the safeguards are met, the law in effect presumes that the patient would have given consent had he or she been able to-because the treatment is in his or her best interests.

In each of these cases, consent is either volunteered or presumed; and in each case the subject's interests are paramount.

\section{Animals and consent}

Animals, of course, cannot give consent. In a therapeutic setting, they rely on their owners to give consent on their behalf. The fact that treatment may be experimental is no bar, provided again that the particular animal may benefit. As with patients lacking capacity, the consent of the animal is, in effect, presumed if the treatment is in its best interests.

Animal experiments, by contrast, never benefit the particular animals experimented upon and are not designed to. This is why the correct comparison is with non-consensual experiments on people. A devil's advocate might nevertheless argue that, as with people without capacity, a lab animal's consent might sometimes be presumed. He might paint an optimistic scenario in which a mouse is adequately fed and watered and is housed in a laboratory in a way that is environmentally enriching and comfortable. He might also ask us to imagine that the procedures to which the particular 
mouse is subjected are only mild, such as the occasional taking of a blood sample, and not the more invasive procedures to which many lab mice are subjected (such as the creation of cancerous tumours and ascitic monoclonal antibody production).

Of course, the mouse would prefer not to be subjected to any procedure. But a rational mouse in its position, so the argument could run, might conclude that its life in the laboratory is nevertheless better than life outside, where it would have to search for food and live in constant danger from predators. It might judge that the loss of freedom and the occasional mild discomfort (under our scenario) are worth the security gained. Even if is likely to be killed prematurely, it might reason that, but for its proposed use in an experiment, it would not have been born in the first place. Better to have a life cut short than no life, it might ponder in an insightful moment.

In reality, even our hypothetical mouse might well prefer to take its chances in the wild. It is a reasonable assumption that primates and domesticated species such as dogs and cats would be most unlikely, under any circumstances, to swap freedom in the wild or a comfortable home for life in the laboratory. Clearly, one could not look to researchers (or government inspectors immersed in the culture of lab animal research) to make an impartial judgement that an animal would have given its consent had it been able to. In addition, the suffering experienced by lab animals is usually greater than mild discomfort, often far greater, even ignoring the distress caused by confinement in unnatural conditions.

However, the important point for the purpose of philosophical discourse is that it is theoretically possible to conceive of cases where, looked at from an animal's perspective, the cost of being involved in an experiment might be outweighed by other considerations, in the same way as a poor student might make that judgement. Crucially, however, prevailing morality treats the two situations very differently. The law is simply not interested in whether an animal might be presumed to consent to an experiment. Its interests are overridden, ultimately rendered at naught. By contrast, the interests of the human experimental subject are always paramount. Intriguingly, the Helsinki Declaration and the Nuremberg Code embody the fundamental difference in approach. The Helsinki Declaration requires that experiments on people must, where appropriate, be based on information derived from animal experiments; and the Nuremberg Code says that the experiment "should be ... based on the results of animal experiments".

In other words, the codes stress the importance of consent with experiments on people but brush it aside when it comes to experiments on animals. There is a complete absence of consistency. Lord Winston recently fell into the same trap. ${ }^{19}$ He complained that doctors trying out new IVF techniques were effectively experimenting, without informed consent, on patients and babies. His solution? More experiments, necessarily without any consent, on apes and other primates.

\section{Benefit to other animals}

It is often pointed out, in defence of animal experiments, that animals also benefit from them (from the development of veterinary drugs and so forth). So they may, although in fact most experiments on animals for the benefit of animals are in the context of the farming and pet food industries-in other words, for (human) commercial benefit. In any event, here again the glaring inconsistency in approach manifests itself. The proposition is that it is justifiable to experiment on, say, a dog (against its will) so that dogs as a species may benefit. But if that is right, it must, by parity of reasoning, also be justifiable to experiment on a person (against his will) so that people generally will benefit. However, very few pro-vivisectionists subscribe to this view, at least openly.

\section{CONCLUSION}

Experiments on animals and non-consensual experiments on people are obvious comparators because both involve physical and psychological suffering for an unwilling, sentient victim. In each case consent is neither sought nor presumed and the victim is not the intended beneficiary.

However, society treats the two cases very differently. This is because ethical sleight of hand is deployed. Different ethical principles are applied to the two types of experiment.

With non-consensual experiments on people, a deontological approach is taken. The prevailing view is that such experiments are inherently wrong, whatever the potential benefits to others. Even where consent is given, the interests of the experimental subject are emphasised. The Helsinki Declaration states as one of its key principles: "In medical research on human subjects, considerations related to the well-being of the human subject should take precedence over the interests of science and society". Science engages in a self-denying ordinance: the interest of the individual trumps that of humanity as a whole, even though this probably slows the search for a cure for Aids.

With animals, by contrast, the approach is a kind of utilitarianism. The law allows scientists to cause pain to animals if others might benefit. The Royal Society has recently argued that it is the alleged benefits of animal experiments which justify them. What it apparently failed to notice is that, if all that was needed for moral justification was a successful outcome, experiments on people would also be justifiedindeed, much more so because people are indisputably a much better scientific model than animals for inquiries into human disease.

Some people, of course, do adopt a utilitarian approach to non-consensual experiments on people. The BMJ's correspondent at the Nuremberg trial of Nazi scientists, Kenneth Mellanby, was prepared to justify those experiments which produced benefits. For example, he praised the notorious paper on typhus vaccines which an SS medical officer, Erwin Ding, published in 1943 as an "important and unique piece of medical research" which might lead to 20000 people being saved for every victim of the research. ${ }^{20}$ We have, fortunately, advanced as a society from the Machiavellian ends and means guide to a moral life-except when it comes to animals.

In making the sort of moral judgement discussed in this article, the best guide, as Shylock realised, is to empathise. The New Oxford Dictionary of English defines empathy as "the ability to understand and share the feelings of others". The Oxford English Dictionary definition is a little more sophisticated: 'the power of projecting one's personality into (and so fully comprehending) the object of contemplation'. As a moral principle empathy finds best expression in St Matthew's Golden Rule: "Do unto others as you would have them do unto you". If I do not want pain inflicted on me, I should not inflict it on others. The reason we should include animals in our circle of compassion, as Albert Schweitzer put it, is because they, too, can suffer.

The ancient Greek poet Bion summarised it in this way: "Boys stone a frog in sport, but the frog dies in earnest". In other words, we should look at things from the perspective of the victim-human or animal-not that of the would-be exploiter. By this yardstick, animal experiments must be immoral, just as non-consensual experiments on people are. In each case, the degree of immorality is in direct proportion to the degree of suffering caused-experiments causing severe suffering are more immoral than those causing only mild, transient suffering. 
Consistency demands that, if we condemn one form of highly invasive physical exploitation, we must condemn all forms. In matters of ethics, the identity of the victim-black or white, Aryan or Jew, man or woman, human or nonhuman animal-should be irrelevant.

\section{NOTE}

David Thomas is a solicitor, specialising in animal protection and human rights law. He is legal adviser to the British Union for the Abolition of Vivisection and chairman of the Royal Society for the Prevention of Cruelty to Animals. The views expressed are his own.

\section{REFERENCES}

1 Taken on Trust (1993)

2 Protocol to the Amsterdam Treaty.

3 EC Directive 98/44

4 See decision T 19/90 (the oncomouse).

5 Section 2(1) of the Animals (Scientific Procedures) Act 1986. EC Directive 86/ 609 uses the same phrase in its definition of "experiment".

6 Animal Procedures Committee. Review of the cost-benefit assessment in the use of animals in research (June 2003).
7 Hansard HoC cols $1129 \mathrm{~W}$ and 467W, 6 and 25 February 2004 respectively. 8 Mossner EC (ed). A treatise on human nature (1739/40). London: Penguin Books, 1969.

9 Smith A. The theory of moral sentiments (1759). Edited by Baird RM, Rosenbaum SE. Prometheus Books 2000.

10 Smith Kline \& French Laboratories Ltd $v$ Licensing Authority (Generics UK) Ltd and another intervening [1989] 1 All ER 578.

11 See the memorandum in 2001 from Robert McCracken, an APC member, to the House of Lords select committee on animals in scientific procedures: http://www.publications.parliament.uk/pa/ld/ldanimal.htm (accessed 11 January 2005).

12 Lexchin J, Bero LA, Djulbegovic B, et al. Pharmaceutical industry sponsorship and research outcome and quality: systematic review. BMJ 2003:326:1167-70.

13 Section 5(4) of the Animals (Scientific Procedures) Act 1986.

14 The Ecologist. October 2001

15 See, for example, the US Declaration of Independence (1776).

16 Bentham J. Introduction to the principles of morals and legislation (1789). Prometheus Books, 1988.

17 Oxford University Press, 2nd edition, 1989.

18 See $R(N)$ v Doctor $M$ and others [2002] EWCA Civ 1789

19 News conference, Manchester, 10 September 2003: Birmingham Post, 11 September 2003.

20 The Medical Unit. Trials of war criminals before the Nüremberg military tribunals. Vol II. Washington, DC: US Government Printing Office, 1950:91
Research ethics

\section{Pain, vivisection, and the value of life R G Frey}

\section{Pain alone does not settle the issue of vivisection}

l: his paper, Lab animals and the art of empathy, David Thomas presents his case against animal experimentation. That case is a rather unusual one in certain respects. It turns upon the fact that, for Thomas, nothing can be proved or established in ethics, with the result that what we are left to operate with, apart from assumptions about cases that we might choose to make, are people's feelings. We cannot show or demonstrate that Pol Pot did anything morally wrong; we just have to hope, as seems not unreasonably demanding, that most people feel pretty strongly about large scale slaughter of human beings. Since nothing can be proven, we turn instead to our feelings and the three claims that Thomas features in his paper: that we should empathise with all creatures who can feel pain and suffer; that we should be consistent in condemning things based upon a similar degree of suffering involved and so treat like cases alike, and that we should take consent seriously, and, where the possibility of consent is absent, take seriously the notion of the best interests of the creature involved. Thomas concludes his paper with a succinct statement of his position: "In other words, we should look at things from the perspective of the victim, human or animal, not that of the would be exploiter. By this yardstick, animal experiments are as immoral as non-consensual experiments on people. In each case, the degree of immorality is in direct proportion to the degree of suffering causedexperiments causing severe suffering are more immoral than those causing only mild, transient suffering. Crucially, however, an experiment causing severe suffering to an animal is as immoral as one causing severe suffering to a person."

All animal experiments, therefore, have to be stopped.

There are a number of large scale issues that cannot be addressed here. Is it really true that nothing can be proved or established in ethics? Is it really true that "feelings" are the guide that we have instead to follow? Does it matter that Thomas sometimes writes of pain, sometimes of suffering, sometimes of psychological phenomena presumably under the heading of "suffering" or, more broadly, "harm"? Can a person "feel" one way about a certain case but "feel" another way about a rather similar case? Can we demand that a person feel "consistently" between cases? Does the notion of consent really work in the way Thomas suggests? What exactly does "informed consent" mean, even in the case, say, of an uneducated person? And if the notion of consent appears beside the point in the case of animals, how do we determine "the best interests" of some creature and who gets to do the determination? All of these questions involve large issues-ones that have been much debated both in moral philosophy generally and in the "animal rights/animal welfare" literature. Different answers to them seem likely to yield different positions on the issues involved.

Before I turn to the two related issues that I wish to address, I should note what might appear to many to be an important aspect of the appeal to empathy. We must, says Thomas, put ourselves into the shoes of those on whom we are proposing to experiment. The presumption is that we and they will not want done to us whatever is in question-for example, will not want the pain inflicted on us that the experiment in question will involve. It is not clear, however, that this will show that inflicting that pain is wrong. Put differently, empathy will get us, as feeling creatures, to put ourselves into the positions of other feeling creatures, to the fullest extent we can; but how do we get from there to the claim that inflicting pain in this case is wrong? What seems required here is a claim that nothing at all could ever justify the infliction of pain, at least in the case of a creature who does not want it, but this seems to be precisely what is at issue with the vivisectionist. What can seem unclear, then, is that the appeal to empathy actually addresses the vivisectionist: the vivisectionist need not claim that the animal does not feel pain, or that the animal wants the pain that is to be inflicted, or that feeling creatures may not empathise with other feeling creatures. The vivisectionist's question is whether the infliction of that pain 
can be justified, and the appeal to empathy does not seem to address that point. For example, in numerous school systems around the world, corporal punishment is the norm: I may well empathise with a student who, through misbehaviour, is presently being paddled, but "my feeling for him" will not show that it is wrong or unjustified to paddle him. Someone responds: "But you yourself would not want to paddled". No, I would not, but that does not show that it would be wrong or unjustified to paddle me if I misbehaved. Empathy is directed towards getting me to feel the animal's pain, but I can empathise and still think the infliction of pain is the right course of action.

There are two related issues that seem very much in need of detailed discussion if we are fully to understand Thomas's claims. First, we need to know whether something can compensate for or offset pain and suffering. He seems to write as if nothing could do this yet it seems that much of modern life involves this sort of thing. For example, consider harm in one of its senses: our tax system imposes harms on one person and, by redistribution, confers benefits on others; in the US, in nearly all school districts, single people are taxed in order to support the children of married people in the schools; conscription uses some people in order to defend the lives and possessions of other people. And so it goes. In most such cases, someone will argue that the person who is harmed or from whom costs are exacted in fact enjoys some benefit-for example, single people enjoy all the many benefits of being surrounded by the educated children of married peoplebut that benefit is nothing like the very direct benefit enjoyed by married people in having their children educated in part at other people's expense. Now one may object to all this; indeed, part of what attracts some people in ethics to rights theory is that strong rights may resist this kind of trade off, so that one may not justify the violation of one's person's rights by the benefits conferred on one or more other people. Thomas, however, says nothing about any of this in any extended fashion, and he does not make his position turn upon the possession of rights by animals. Arguments from benefit appear to be central to most cases for animal experimentation so something needs to be said in a certain amount of detail about why pain and suffering cannot be part of such arguments from benefit.

The second and much more important issue is indeed touched upon by Thomas but not in a way, I think, that captures its true significance. This is the issue of the value of a life. Thomas warns us that thinking lives can be of different value can lead us to all kinds of terrible outcomes, and the Nazi camps once again are brought forth in evidence of these dangers. This is, in disguise, a slippery slope argument, and I think evidence is required in order to convince me that regarding anencephalic infants or people in permanently vegetative states as having lives of very much lesser value than normal adult human life leads straight to the Nazi camps. (Also, see the examples below.)

To my mind, the value of a lifehuman and animal-is a function of its quality, its quality a function of its richness and content, and its richness and content a function of its capacities for enrichment and different types of contents. When we see before us every day human lives of desperate quality, lives which have plummeted to depths that we would not wish even our worst enemies to have to enjoy, it seems to me mere pretence to insist upon the intrinsic or inherent equality in value of all human lives. Certainly, today, when physician assisted suicide is increasingly before us as an option, many people whose quality of life has fallen to a tragic degree regard as mere fantasy, perhaps enforced by our Judaic Christian past, the claim that their lives are as valuable as they always were. To be sure, one can try here to introduce some distinction between the intrinsic or inherent value of a life and the quality of a life; but if the value of a life is not to consist in its quality, in what, then, is it to consist? We need an answer. In some religions, we were told that our lives were all equal in value "in the eyes of God", and this, I assume, since many lives were obviously blighted and impaired to very tragic degrees, may have been comforting. How are we to understand this kind of claim today, in the light of the obvious blight and impairments? It seems almost cruel to tell someone in the final stages of amyotrophic lateral sclerosis that their life is still as valuable as it was, when they often now beg desperately for release from that life.

The truth is, I think, that some human lives have fallen so far in value, quality, richness, and scope for enrichment that some animal lives exceed in value those human lives. Anencephalic infants and people in permanently vegetative states are cases in point. It was comforting in the past to think that all human lives were more valuable than any animal life, but the quality of life of a perfectly healthy dog or cat must vastly exceed the quality of any human life that has ceased to have experiences of any sort, that has ceased to have in essence any sort of content. I am not a speciesist but the capacities and scope for enrichment of a life of a normal adult human arguably exceeds that of any rodent found in our labs, with arguably higher quality and value. To confine our judgments about humans and rodents only to the issue of whether they can feel pain and suffer, as Bentham and Thomas would have it, strikes me as ignoring all the capacities and abilities that go toward enriching a life and so toward giving it a quality and value. This strikes me as precisely something that we must not do.

If we have to experiment (and I do not here assume that we do, in all cases where present experimenters assume learning, education, and pursuit of knowledge is at stake), then which life do we use? We use that life of lower quality, and we have a non-speciesist way of determining which life that is. Merely focusing upon pain and suffering does not get at that way of determining quality of life. Notice, too, that this picture meets Thomas's demand of consistency as between humans and animals. How can we justify an experiment on a perfectly healthy rodent with an experiential life as opposed to an anencephalic infant with, so far as we know, no experiential life at all? I do not deny that there would be side effectsfor example, outrage, if we actually moved to experiment on such an infant. (Though it is worth remembering that the matter is no longer quite so clear cut in this regard as it used to be.) In, I believe, 1996, a white paper of the American Medical Association proposed that anencephalic infants be regarded as organ donors. (Subsequently, the association as a whole withdrew this white paper, but the issue of whether such infants may be so regarded is now an issue of debate.)

of course, we can argue about whether something is a benefit; about whether we need this particular bit of knowledge; about how likely we are really to learn anything from continuing repeating this or that experiment, and about whether any piece of knowledge is worth the lives of this many animals or worth this degree of pain and suffering. Where we have doubts on these accounts, we may refuse to go forward with an experiment: but where we come to satisfy ourselves on these accounts, is not the condition of the argument met? This in part, I think, is why some people today argue that animal models of any disease, illness, or surgical procedure will never be sufficiently reliable to be used-a claim, of course, which others dispute. Then, they may claim that they never have to face the prospect of using the being of lesser value. 
To be sure, much needs to be filled in and defended in this picture of the value of human and animal life, but it in no way accepts the equal value of all human lives or the claim that all human lives are more valuable than all animal lives. It ties the justification of experimentation to issues of benefit and to the quality and value of a life and so to themes that lie well beyond any mere focus upon empathising with the pains of animals. For a presentation and defence of some of the arguments that fill in the position sketched in this paper, see the papers and chapters listed below. ${ }^{1-7}$
$J$ Med Ethics 2005;31:202-204. doi: 10.1136/jme.2004.008367

Correspondence to: R G Frey, Department of Philosophy, Bowling Green University, Bowling Green, Ohio 43403, USA; rfrey@bgnet.bgsu.edu

\section{REFERENCES}

1 Frey RG. Medicine, animal experimentation, and the moral problem of unfortunate humans. Social Philos Policy 1996;13:181-211.

2 Frey RG. Moral community and animal research in medicine. Ethics Behav 1997:7:123-36.

3 Frey RG. Organs for transplant: animals, moral standing, and one view of the ethics of xenotransplantation. In: Holland A, Johnson A, eds. Animal biotechnology and ethics. London: Chapman and Hall, 1998:190-208.

4 Frey RG. Justifying animal experimentation: the starting point. In: Paul EF, Paul J, eds. Why animal experimentation matters. New Brunswick: Transaction Publishers, 2001:197-214.

5 Frey RG. Animals. In: LaFollette H, ed. Oxford handbook to practical ethics. New York: Oxford University Press, 2003:161-87.

6 Frey RG. The ethics of the search for benefits: animal experimentation in medicine. In: Gillon R, ed. Principles of health care ethics. New York: John Wiley, 1994.

7 Frey RG. The ethics of using animals for human benefit. In: Mepham TB, Tucker GA, Wiseman J, eds. Issues in agricultural bioethics. Nottingham: University of Nottingham Press, 1995:335-44.

\section{COMMENTARY}

Professor Frey expresses surprise at my assertion that, ultimately, nothing is provable in ethics. What about Pol Pot's atrocities, he asks-surely we can all condemn them? Let us take a more recent example, the Beslan school massacre. The terrorists appear to have weighed against the unquestionably serious harm to the children (and adults) the boost to their cause which they judged the attendant publicity would achieve. I may believe that even to attempt such a utilitarian assessment is obscene, and most would no doubt agree. I cannot, however, prove that this is the wrong approach. A few people, at least, take a different view.

The example shows the problem with utilitarian assessments where the harm is both certain and direct, the victims and beneficiaries are wholly distinct and the victims have no say in the assessment-precisely the pattern with vivisection.

I do not, of course, advocate an ethical free for all. As I suggested in my article, an ethical response must be informed, intellectually coherent, and above all, consistent across similar issues. Empathy and consent are key factors: hence my comparison of animal experiments with nonconsensual experiments on people.

Professor Frey's foray into the apparently unconnected issue of euthanasia is instructive. The key to voluntary euthanasia, which I personally support if rigorous safeguards are in place, is the informed consent of the patient. The practice is a form of suicide, an act of free will, albeit one requiring the assistance of another person. Consent is crucial with permissible experiments on people, too, and the absence of even presumed consent is, I have suggested, what makes animal experiments ethically illegitimate.

Involuntary euthanasia is much more problematical. But if it is ever legitimate-where a baby's suffering is enormous and will be never ending, some argue-this is surely because it is what we would wish for ourselves in that situation. In other words, we would empathise with the baby and presume his consent to the ending of an intolerable life.

Professor Frey says he is not a speciesist and indeed shows it by suggesting that the life of an anencephalic child is less valuable than that of a healthy dog. The ethical key, he goes on to say, is not sentiency but "the capacities and abilities that go towards enriching a life and so toward giving it a quality and value". But why? Take, on the one hand, someone who helps thousands through his work and who leads a culturally rich life and, on the other, a drunken slob who beats his wife and children and spends his days watching soaps. We might well say that the life of Renaissance Man has more quality and value than that of Uncouth Brute, but would it follow that the former could with ethical approval cause harm to the latter for his own benefit? Surely not. The original Renaissance Man, Leonardo da Vinci, was opposed to vivisection, incidentally.

Professor Frey is correct that I do not base my opposition to animal experiments on a concept of animal rights. This is because ethics is about human behaviour, and ultimately rights are only accorded, whether to people or animals, if it is considered that freedom of action should be curtailed so that the group in question is protected from harm. Rights are merely the flip side of someone else's obligations.

I maintain that the best guide to the obligations we should assume to a potential victim is to put ourselves in his or her shoes, particularly where the harm is direct and serious. Empathy is a multifaceted concept and has generated a significant body of research among behavioural psychologists, but as Martin Hoffman and others have argued, it is closely linked with moral precepts. This is a philosophy based on intellectual rigour, not emotion as Professor Frey appears to think, although it does focus on the feelings of the putative victim.

Ultimately, I cannot prove it is wrong to cause pain (or other serious harm), without any form of consent, to an animal for the perpetrator's own benefit, any more than I can prove that it is wrong to cause pain to another person for the perpetrator's benefit. Even religious based ethical beliefs are not empirically provable, at least in this life. I am entitled, however, to expect a consistent response to comparable situations.

There are, as Professor Frey indicates, exceptions to every moral principle-in the context of causing physical harm to others, self defence, principally_-but they have to be applied consistently, not opportunistically. Ethics should not depend on what the group with power can get away with. That is precisely what vivisection involves.

D Thomas wdcthomas@onetel.com 